\title{
¿Por qué es necesaria una historia de la semiótica? En busca de la identidad y la memoria a reconstruir
}

\author{
Elizabeth Parra Ortiz ${ }^{1}$
}

Evaluado: 24/05/2020 / Aceptado: 30/05/2020

Resumen. Este ensayo tiene por objetivo reflexionar sobre la historia intelectual nuestra y las teorías que se han venido siguiendo con la esperanza de incrementar nuestra mirada y visualizar qué historia de la semiótica amerita ser narrada para orientar nuestro trabajo y de paso levantar nuevas propuestas teóricas o quizás otras historias que pudieran enriquecer a la disciplina.

Palabras claves: historia de la semiótica, arqueología, identidad, memoria

\section{[en] Why is it necessary a history of Semiotics? In search of an Identity and a Memory to rebuild}

\begin{abstract}
The purpose of this essay is to reflect on our intellectual history and the theories that have been followed in the hope of increasing our gaze and visualizing what history of semiotics deserves to be narrated to guide our work and incidentally raise new theoretical proposals or perhaps others stories that could enrich the discipline.

Keywords: history of semiotics, archeology, identity, memory
\end{abstract}

Sumario: Entrada. 1. ¿Quiénes se han preguntado por la historia de la semiótica? Eco, Peirce, Vidales, Castañares. 2. ¿Qué historia de la semiótica puede dar satisfacción a estas necesidades? Salida. Bibliografía.

Cómo citar: Parra Ortiz, E. (2020). ¿Por qué es necesaria una historia de la semiótica? En busca de la identidad y la memoria a reconstruir, en CIC. Cuadernos de Información y Comunicación 25, 47-60.

Qué consecuencias puede tener para la semiótica el que los semiólogos no hayan sido capaces de articular un relato que hable de las vicisitudes por las que ha pasado el pensamiento semiótico y, en cambio, qué podría aportar ese mismo relato, si llegara a articularse y difundirse. Castañares (2017: 203)

\footnotetext{
1 Universidad de Concepción, Chile.
}

E-mail: elparra@udec.cl 


\section{Entrada}

Hoy referirme al legado de Castañares (2017) me trae a la memoria dos situaciones que me remiten al trabajo de investigación que estoy terminando ${ }^{2}$ donde -justamente- una de las preguntas que me acompañó durante todo el proceso fue cómo articular la historia de un pensamiento con tantas entradas sin tener un referente común que me permitiera conocer cómo se habían resuelto los problemas centrales en otras épocas $\mathrm{y}$, dos, la reiterada vinculación que los investigadores chilenos establecen entre semiótica y comunicación, específicamente, con la teoría de la comunicación. Precisamente, las entrevistas a investigadores chilenos y lecturas de investigadores tanto latinoamericanos como europeos y estadounidenses, fueron dando forma sobre estas discusiones (Castañares, 2014, 2017; Eco, 2007; Martín-Barbero, 2001; Peirce, 1897; Serrano, 1998 y Vidales, 2008, 2009, 2010, 2011), que apuntan a desentrañar la búsqueda de la genealogía de la semiótica y de la comunicación al mismo tiempo.

Vidales ha publicado varios estudios donde se da cuenta de la escasa preocupación por parte de los investigadores sobre los ejes fundacionales de la teoría de la comunicación y su estrecha relación con la semiótica, que a la larga ha llevado a confusión. Para nadie es desconocido que se proponga como fundadores de la semiótica a Saussure y Peirce a finales del siglo XIX y comienzos del XX. Lo que a continuación de ese relato conocido sigue, son una serie de trabajos de reconstrucción histórica del pensamiento semiótico que varían en forma sustancial según sus puntos de partida, así como por el tipo de recorrido que plantean, lo que sin duda ha conllevado a la aparición de nuevos problemas.

Es importante considerar que la reconstrucción histórica que se elija determinará un tipo de semiótica vinculada a algunos objetos, a una línea de pensamiento filosófico, nos ofrece la posibilidad de visibilizar algunos aspectos y ocultar otros (Vidales, 2010: 70). Lo cierto es que cada historia de la semiótica deja en claro que hay varias semióticas en el concierto de las disciplinas. De ahí, que volvamos a preguntar ¿qué historia seguir, por qué esa y no otra y para qué? Preguntas válidas si aceptamos que muchas de las historias narradas hasta la fecha se refieren al signo y no propiamente a la semiótica como acertadamente señala Vidales. En esta oportunidad, deseo hacerme cargo de la primera situación inicial que he propuesto, desde la mirada de Wenceslao Castañares acompañada de Umberto Eco.

Al leer sus escritos, me queda claro a simple vista que la primera impresión al estudiar la semiótica pudiera parecer un asunto de fácil comprensión en la medida que respondiera a un campo de estudio tradicional, homogéneo y delimitado. No obstante, sucede todo lo contrario. Las disensiones entre los investigadores que la cultivan son de tan diversa índole que obligan a ser más cautelosos a la hora de intentar delimitar sus bordes, reconocer su identidad y definir el lugar que ocupa en el marco de las otras disciplinas.

Según Fabbri (2004), el problema radica en que la semiótica debe estudiar el sistema y los procesos de significación, y superar la visión fragmentada y binaria del signo propuestas por Saussure. Por tanto, la necesidad de asumir la interdisciplinariedad como método, otorga la posibilidad de desjerarquizar los saberes y los

Proyecto Asociativo Cartografía de investigaciones de Semiótica en Chile. Código 213.174.006-1.0. 2014-2019 y financiado por la VRID de la Universidad de Concepción, Chile. 
conocimientos, y hacerse cargo más bien de las dinámicas y transformaciones de los procesos de significaciones que se buscan interpretar más que de los resultados.

De hecho, al decir de Castañares podríamos hablar y reflexionar más bien acerca de una historia del pensamiento semiótico. Incluso siendo más precisos, a su juicio, lo que se ha estado haciendo hasta la fecha es la interpretación de un pensamiento desde una mirada semiótica, pero en ningún caso respondiendo a una genealogía de la semiótica en sí misma, o en palabras de Eco (2016), reconstruyendo la historia de la semiótica y en ese caso, estamos ciertos y compartimos su preocupación por la inmediatez empírica con que se han tratado los problemas semióticos replegándolos más bien al análisis que muchas veces no apuntan a la generación de un conocimiento prospectivo y que no basta con lo descrito, sino se debe trascender hacia otros niveles de teorización para no caer como plantea Vidales (2010) en relativismos teóricos.

La crítica que afirma Castañares la comparto porque sin duda la semiótica en estas latitudes latinoamericanas se ha visto más bien relegada a una suerte de herramienta metodológica (Parra, 2013), producto quizás, primero, por los paradigmas que se han impuesto para el desarrollo de la investigación científica en general; segundo las raíces disciplinarias de aquellos académicos formados en Francia en la década del 70, particularmente, al alero de las escuelas estructuralistas; y tercero, por la falta de programas de especialización que pudieran permitir la creación de Escuelas para estudiar a fondo su genealogía y de ese modo proyectar y difundir el campo disciplinar.

Esta necesidad de dar cuenta del lugar de la semiótica y su desplazamiento hacia la interrogante por su utilidad es recurrente, da cuenta de los diferentes contextos de los académicos que interpelan a la semiótica y que en este proceso de tanta generalidad por intentar tener una mirada lo más abarcarte posible, pueden caer en confusiones y perder rigor científico.

Eco - sin duda- influyó en Castañares para que haya iniciado un trabajo riguroso y a la vez detallado; y, de ese modo, iniciar una suerte de oficio de historiador del pensamiento griego y romano, para luego pasar por la Edad Media, e ir descubriendo y desentrañando los problemas del signo, y, por ende, semiótico para construir la historia de la semiótica. Infelizmente, su proyecto de alta envergadura teórica y sistémica, que pretendía llegar hasta la época moderna, quedó incluso.

Las lecturas sobre los escritos del académico Castañares me permitieron reafirmar la necesidad de develar los orígenes y también que el pensamiento semiótico ha estado asociado a los estudios del lenguaje y de la cultura desde los primeros indicios de la cultura occidental. En efecto, desde las primeras visiones griegas, sabemos que la historia del signo asociado al lenguaje fue la preocupación fundamental, lo que derivó en dos paradigmas que hasta hoy nos acompañan: la mirada universalista, representada por Platón, y la otra, convencionalista, cuyos autores más relevantes son los sofistas. Para la primera posición con un carácter universal, el logo se alzaba para nombrar (formalmente), las cosas, con contenidos y significados de carácter racional y con la presencia de problemas permanentes. Mientras que, para el convencionalismo, el estudio del lenguaje fue un fenómeno social (histórico) y sus significados se muestran variables según sus condicionantes externas, que se acerca más a las matrices sociohistóricas-culturales latinoamericanas que compartimos (Muñoz, 2005; Martín-Barbero, 1988).

De ahí que, en un sentido más preciso podemos hablar y reflexionar acerca de una historia del pensamiento semiótico y, en ese caso, resulta más accesible el aporte que desde los griegos han hecho al desarrollo de un pensamiento que diversos intelectua- 
les y escuelas han hablado sobre el signo, el lenguaje y los procesos de significación para referirse a la semiótica. Es cierto que a lo largo de la historia hay tendencias que han decaído o desaparecido, pero al mismo tiempo siguen surgiendo otras. No obstante, esas miradas fragmentadas hasta hoy impiden lograr esa mínima unidad, que todos han intentado buscar, con el resultado frecuente de crear semióticas adicionales (Cfr. Beuchot, 2004: 4) o aplicadas en nuestro concepto.

El trabajo de Castañares, especialmente el último, su propuesta magistral Historia del pensamiento semiótico I y II constituye un aporte vital a la comprensión de la semiótica desde la perspectiva que me interesa desentrañar, esto es, desde la genealogía y los fundamentos de una disciplina. Tal como lo manifiesta Castañares, en el primer tomo dedicado al periodo de la Antigüedad: "El interés por los signos fue, en primer lugar, como ha ocurrido siempre, un interés de carácter práctico. Formaba parte del saber de cazadores, marineros, adivinos, estrategas, poetas y médicos. Pero en un determinado momento se hizo más general y el saber sobre lo que los signos hacen o pueden hacer quiso poseer una generalidad que ya no era la de un saber práctico, sino la de un saber experto con pretensiones de convertirse en episteme" (2014: 1).

No se pueden desconocer otros aportes con distintas orientaciones que tienen la pretensión de ser historias más o menos breves de la semiótica, como las introducciones a la semiótica, textos que abundan, pero que resultan insuficientes por diversos motivos. Como señala Fabbri "uno de los grandes problemas de la semiótica contemporánea es que produce muchos textos, pero que no produce crítica sobre los textos que producimos. Asimismo, otro es que, al menos en Italia, hemos acumulado en los últimos años cerca de 20 textos introductorios a la semiótica. Yo encuentro esto muy grave, muy peligroso, porque [...] significa que no hay un corpus unificado de conceptos y que, por ende, existe una debilidad, una incerteza, de las orientaciones semióticas" (Busso, 2015: 91).

Castañares coincide con la postura de Fabbri al afirmar que la pobreza de recursos y la inexistencia de obras accesibles que traten de dar visiones de conjunto bien fundadas que puedan explicar el escaso conocimiento que en general tienen los investigadores de la historia de su disciplina, llevan a preguntarse qué razones se aducen para que suceda este fenómeno.

En Chile, junto con las diferentes aproximaciones, se observa un desarrollo disparejo y precario de la semiótica, cuestión que tiene mucho que ver el interés y motivación por parte de los investigadores como también con las condiciones histórico-sociales y culturales que definieron de alguna manera su arribo al país y de la institucionalidad reinante en aquella época y en el presente.

Por un lado, en Chile no existen escuelas de pensamiento que induzcan a los interesados en semiótica a profundizar en su genealogía. Hay intentos de levantar propuestas como seminarios o jornadas de reflexión, pero que no tienen continuidad en el tiempo y, por otro lado, la disciplina no es reconocida como parcela epistémica importante a la hora de ser enseñada, pues - habitualmente - se encuentra restringida a una herramienta de análisis a nivel discursivo, o bien, como una unidad de aprendizaje de tipo teórico apelando a la lingüística de Saussure. De tal modo, que la historia de la semiótica aún no ha sido narrada. Lo que se conoce como fundación, comienza a principio del siglo XX a partir de los dos referentes antes señalados: Saussure y Peirce. 


\section{1. ¿Quiénes se han preguntado por la historia de la semiótica? Eco, Peirce, Vidales, Castañares}

Antes de responder a esa pregunta, conviene tener presente lo que Escudero (2017), afirma sobre la relevancia de la perspectiva histórica, a propósito del homenaje que se le brindara a $\mathrm{Eco}^{3}$ en la revista deSignis, como uno de los maestros que se preocuparon de la materia:

la historia de una disciplina es también la historia de las preguntas que esa disciplina ha colocado en referencia a su objeto de estudio y las variaciones que han tenido lugar precisamente sobre la naturaleza de ese objeto. Pues, una perspectiva histórica no es solamente discernir qué nudos teóricos han sido fundamentales, sino también proponer un paradigma desde dónde organizar estos objetos. La perspectiva histórica es un modo de construcción del objeto, no por cierto el único, pero sí útil y adecuado para conferir identidad a una disciplina” (2016: 10).

Esta idea es compartida por Castañares, a través de un excelente artículo que escribió titulado La arqueología de la semiótica (2017), a propósito de la celebración de los 30 años de la FELS en Bogotá, Colombia. Allí por primera y única vez tuve la oportunidad de dialogar con él sobre la semiótica y su perspectiva histórica, asunto que me ocupaba de manera especial.

La enseñanza que se extrae de la lectura es que ocuparse de la historia de una disciplina es estar siempre en camino de algo, pero sin saber el fin. El trayecto no conduce a un destino definitivo, como quien recorre con la vista un árbol desde la base hasta la copa. El trayecto se asemeja más bien a la exploración de un laberinto que se ramifica y entrecruza. Ello es así porque los signos del pasado ofrecen interpretaciones según las preguntas que formule el historiador, en un diálogo de las voces del pasado con las inquietudes del presente (Laborda, 2011: 55).

El esbozo de una historia de la semiótica, Eco la presentó por primera vez en La Coruña, pero venía gestándola desde hacía dos décadas cuando formuló un manifiesto historiográfico y que publicó en sus obras de 1984 y 1990. Sin embargo, esa línea de investigación había quedado oculta por tareas más llamativas del momento en relación con semiótica teórica y de la cultura. Es en Semiótica y filosofia del lenguaje (1984), donde declaró su interés por volver a las fuentes filosóficas para proponer una historia de la semiótica. En ese texto explica que, para aplicar su propuesta en esta obra de filosofía del lenguaje, desarrolló un tratamiento histórico de los cinco conceptos básicos en semiótica a su entender: signo, significado, metáfora, símbolo y código, y agrega que "me he convencido cada vez más de que, para comprender mejor tantos problemas que aún nos preocupan, hay que proceder a la revisión de los contextos en que una determinada categoría ha aparecido por primera vez" (Eco, 1984: 5-6).

Eco propone para la historiografía como modelo seguir la idea de un laberinto de la red o rizoma del callejero porque "No tiene centro, ni periferia, ni salida, porque es potencialmente infinito. Es espacio de la conjetura" (1984: 67) de modo abductivo.

Sin duda, Eco, ha sido y fue el mejor exponente en este estilo de construir conocimiento. Sus obras son reconocidas por la perspectiva histórica que les imprimió

Se recoge en la Revista deSignis ํ25, la ponencia pronunciada por U. Eco en el Congreso de la IASS-AIS de 1979 en Viena. 
a sus textos donde también aflora su veta poética, por ejemplo, cuando describe que "un bosque es, Borges, un jardín cuyas sendas se bifurcan" (Eco, 1983: 67), pues por sendas o en la espesura cada cual traza su propio recorrido de la mano de quien la narra.

La travesía de un historiador o cartógrafo como lo llama Martín-Barbero (2001) consiste en estar en elecciones continuamente, porque su discurso se transforma a partir de una mirada histórica, la que se va acumulando en la memoria de una travesía que devela los criterios adoptados en un momento histórico, como también los hallazgos que van emergiendo a medida que avanza el proceso.

Luego de varios años de estudio y revisión de trabajos, entre ellos Vidales (2010), un académico mexicano, me asaltaba la inquietud de por qué era necesario que el investigador se refiriera a la genealogía de la semiótica para construir conocimiento y seguir reproduciendo de lo que ya está dicho. Sin duda, será Castañares (2017) quien responde y me aclara la relevancia de volver a los orígenes porque "la historia de la semiótica es una respuesta a la pregunta por su identidad y también a la pregunta sobre el lugar que la semiótica ha de ocupar entre las ciencias sociales" (p. 203).

Dos conceptos que, aunque se han repetido en el tiempo no ha habido estudios que se hubiesen hecho cargo acerca de la identidad y la memoria que acompaña a una disciplina como en este caso. Incluso, agrega, la reflexión sobre lo que la semiótica es hoy debería incluir también el lugar que ocupa (la semiótica) en el contexto disciplinar, cuestión que sigue siendo un problema a definir en el marco de las otras disciplinas.

Es indudable que existen varias razones que pueden poner de manifiesto la urgencia de contar con una historia de la semiótica y que hasta la fecha no se había iniciado. Sin embargo, las razones que menciona Castañares son lo suficientemente claras para que la tarea de la reconstrucción de la tradición ocupe un lugar de privilegio en los estudios semióticos.

La preocupación de Castañares no es reciente, atraviesa su trayectoria como investigador y docente. Él, ya lo había advertido en el Congreso de la IASS de 2014 efectuado en Sofia, cuando Uspensky respondía a una pregunta de Kull y Velmezova (2014: 532), sobre la situación de la semiótica diciendo, que, en la actualidad, "la semiótica teórica estaba estancada". A juicio de Castañares eso sucede porque la semiótica hoy está volcada hacia el análisis de discurso. Es una de las inferencias que también puedo ratificar en mi país. Aquellos actores claves que se dedican a cultivar la disciplina manifestaron a través de entrevistas que, utilizando una metáfora, la semiótica es una "caja de herramientas"4 desde donde se puede entrar, extraer aquellos elementos que interesan, y luego salir.

En realidad, como lo señala Castañares la cuestión del análisis no es el problema porque todos nosotros en algún momento lo hemos utilizado, pues del análisis de la experiencia proviene muchas veces la renovación de teorías, por ejemplo. La dificultad a mi entender radica en que mucho de los análisis responden más bien a adecuaciones teóricas sin posibilidad de poner en duda lo dicho, y sin descubrir algo más. Dicho de otro modo, debiéramos ser capaces de salir del esquema descriptivo y detenernos en niveles más profundos de comprensión cómo es la vuelta a los orígenes, aunque algunos sostengan que esa ha sido otra de las razones del estancamiento de la disciplina, estar siempre en perspectiva del pasado.

Concepto este que también nos remite al pensamiento de Foucault. Ver, por ejemplo, Cruz, J. I. (2006). El pensamiento de Foucault como caja de herramientas, Discusiones Filosóficas, 7(10), 183-198. 
A mi juicio, complementando lo dicho por Castañares y como lo he señalado anteriormente en otros trabajos (Parra, 2013; Parra y Otazo, 2014), muchos de los análisis que se hacen obedecen, más bien a una estrategia instrumental de parte del investigador para responder más a exigencias institucionales que a la necesidad de crear conocimiento. Por tanto, si se quiere seguir avanzando, la semiótica tiene que hacer algo más que un análisis. En definitiva, de lo que se trata es de volver a pensar sobre los grandes problemas que debieran orientar el trabajo de la semiótica en diálogo con otros pensadores que lo hicieron en el pasado para observar como resolvieron ellos esas cuestiones de fondo.

Las causas del retraso en la incursión de nuevas tendencias más progresistas para el avance de la semiótica en Chile como un campo de reflexión teórica-crítica, por lo menos se le atribuye una cuota de responsabilidad al desembarco del estructuralismo lingüístico (Saussure), de la mano de quienes se formaron en París, por los años sesenta. Desde esa mirada, si se considera la perspectiva del desarrollo histórico de la semiótica como de la exigencia de carácter teórico, resulta complejo su reconocimiento en el marco del estructuralismo lingüístico, en la medida que dicho paradigma separa la estructura del contexto histórico social para estudiar los fenómenos, ya que no es de su interés, ni lo necesita dado el modelo que creó Greimas y que luego siguieron Barthes y todo el círculo cercano de pensadores para los análisis de los fenómenos sociales-culturales.

Me parece que en parte tienen razón, no obstante, también hay una alta cuota de responsabilidad de los propios investigadores. Castañares (2017) advierte del escaso interés por dedicarse a escudriñar la genealogía y fundamentos de la disciplina más allá del siglo XX.

En Chile, según opinan investigadores del área, primero la semiótica no se reconoce con una sola acepción. Hay una falta de identidad disciplinaria, lo que deviene en la ausencia de reconocimiento científico legitimado por los organismos pertinentes. Entre ellos, la institucionalidad académica, la que no logra instalar a la disciplina como parte de las materias a impartir. En segundo lugar, el uso instrumental de la semiótica como análisis para otras disciplinas y, por último, no menos relevante, es el hecho de la implicación tan profunda que existe entre la comunicación y la semiótica que incluso, a veces, se llegan a confundir.

Considerando lo anterior, y a fin de avanzar en las interrogantes sobre el caso chileno declarado más arriba, nos hacemos cargo de la propuesta de Magariños (2008), quien propone tres acepciones de la semiótica y que, a mi juicio, interpreta a la mirada de los actores en Chile: la primera arranca de una práctica intuitiva asociada con una facultad humana, donde la semiótica siempre ha estado asociada al desarrollo humano, por tanto, aparece como una facultad más del sujeto. La segunda, se asocia a una teoría, la cual, corresponde a la historia y reflexión del pensamiento semiótico (Occidental) donde se estudia el comportamiento y las acciones humanas. La tercera acepción la asocia a una práctica profesional en tanto el ser humano utiliza los conocimientos para reflexionar sobre los comportamientos y, de ese modo, interviene de manera consciente y eficaz en la tarea de atribuirle sentido a los acontecimientos en los que destacan dos perspectivas: una vinculada a la práctica profesional analítica donde los investigadores se concentran en estudiar los comportamientos comprometidos en la interpretación histórica del significado atribuido a entidades de una determinada sociedad; mientras que la otra se vincula a una práctica profesional productiva que pone su acento en la interpretación prospectiva para atribuir signifi- 
cados a entidades en una sociedad determinada, generando a futuro nuevas visiones o paradigmas sobre la semiótica.

En mi país, la semiótica como disciplina aparece asociada a una semiótica aplicada a las prácticas académicas que se evidencia porque la tendencia investigativa a desarrollar es una práctica analítica más que productiva (generación de conocimiento), lo que permitiría entender de alguna manera por qué los investigadores asocian el quehacer de la semiótica a una "caja de herramientas".

Si nos atenemos a la producción de las/os investigadores chilenos, efectivamente, los procesos de la semiótica se aplican al análisis semiótico (Magariños, 2008), que están presentes, aunque no sean reconocidos por los organismos científicos, provenientes de una disciplina social, sino como una herramienta metodológica.

Estas acepciones emergen como una dualidad, desde donde los entrevistados expresan que la semiótica con su amplio y diverso repertorio proveniente de disciplinas particulares, le permiten entrar y salir de su caja y, al mismo tiempo, la misma "caja de herramientas" otorga profundidad a la interpretación que hacen de su objeto de estudio.

La idea que prevalece entre los investigadores es asociar la semiótica a un conjunto de herramientas que proporciona caminos para poder elegir cuál de esos permite aprehender e interpretar la realidad de mejor forma, a partir de la disciplina que se ejerce. Y en otro nivel, se la asocia como una metodología, como una forma de analizar o acercarse a la interpretación de los procesos de significación de una sociedad determinada en un lugar determinado.

En el fondo la pregunta que siempre ha circulado a veces de manera implícita, y pocas veces explicitada como fue el caso del VIII Congreso Chileno efectuado en la Universidad Austral de Chile, cuando se planteó como tema central la búsqueda de los bordes del campo semiótico, asunto que no es nuevo. Aunque lo que sí emerge como nuevo es la urgencia de agregar la historia, el relato en el intento de configurar una identidad para la semiótica, proceso que ha sido lento y como no ha habido claridad al momento de efectuar la pregunta no se ha llenado de contenido.

Imposible desconocer esta preocupación como señala Castañares (2017), a propósito del recuerdo de Eco quien ya señalaba que la gran dificultad es la perseverancia de un interés por parte del investigador. Como el mismo Eco anticipaba en su conferencia de Viena, la preocupación por los signos y su funcionamiento es y ha sido una obsesión del pensamiento de la humanidad, pero lo cierto es que su historia, aún no se ha contado. Y es esa carencia de una voluntad decidida lo que, en mi opinión, ha faltado en todo este tiempo.

Habría que agregar que el hecho que no haya obras al alcance, con una visión de conjunto bien fundadas, puede explicar en parte el escaso conocimiento que en general tienen los investigadores de la historia de la disciplina más allá de los dos referentes clásicos. Entonces emergen otras preguntas ¿qué causas acompañan esta situación de precariedad y del escaso interés por este asunto? o, dicho de otro modo ¿qué consecuencias puede tener para la semiótica el que los semiólogos no hayan sido capaces de articular un relato que hable de las vicisitudes por las que ha pasado el pensamiento semiótico en la historia y, en cambio, ¿qué podría aportar ese relato si llegara a articularse y difundirse? Castañares (2017: 203).

Compleja situación nos plantea Castañares en tanto la historia de la semiótica viene a ser una respuesta a la pregunta por su identidad (Innerarity, 2006), y también a la pregunta sobre el lugar que la semiótica ha de ocupar entre las ciencias sociales, 
pensando que la cultura es memoria, o, en otras palabras, registro en la memoria de lo ya vivido por la colectividad, está ligada inevitablemente a la experiencia histórica pasada, por consiguiente. en el momento de su surgimiento, la cultura no puede ser constatada como tal; de ella se toma conciencia sólo post factum" (Lotman, 2000: 172), por tanto, nos obliga a diseñar una ruta. De ese modo la identidad referida por Castañares es más asunto histórico, que un acto de voluntad. Entonces, cuando se pregunta cómo definir el amplio campo de la semiótica, se está preguntando por aquello que identifica a la disciplina y al mismo tiempo, la distingue de otros campos disciplinares. Y en la respuesta a esa pregunta resulta imprescindible su referencia al origen.

Si se pone atención a la época en que desembarcan los estudios de semiótica en Latinoamérica y lo extrapolamos a Chile, podemos afirmar que no fue bienvenida. Parte de la resistencia hacia la semiótica provenía de las características del continente y del momento histórico- político en que se vivía (dictadura de Pinochet, 1973-1989). Existía un veto a todos los estudios asociados con filosofía o filosofía del lenguaje y, por tanto, los trabajos de Peirce quedaron relegados a los estudios de lógica, en parte. Existiendo asimismo diversos factores que pudieran haber influido.

Por un lado, los radicalismos ideológicos que en la región emergieron, el repliegue de los académicos y las urgencias sociales en aquel periodo demandaban soluciones más o menos rápidas y concretas. Por otro, el rechazo por parte de la academia a los estudios provenientes de las corrientes funcionalistas del norte sesgadas por las lecturas ideológicas y del pragmatismo asociadas a un liberalismo político que desvirtuaban el valor teórico de sus postulados, sin lugar a dudas, influyeron en un cierto recelo contra todo lo que oliera a teoría semiótica, por la complicada jerga especializada y los malabarismos conceptuales en los más altos planos de abstracción. Esta postura nubló las miradas y en lugar de ofrecer estímulo a una incipiente y nutritiva actividad intelectual (Prieto, 1977), produjo una sequía que derivó en los quehaceres hacia dimensiones más concretas y a corto plazo como fue la inserción de la semiótica en el mundo empresarial a través de la publicidad, comunicación audiovisual y periodismo.

La reflexión pone de relieve la pregunta base sobre qué sabemos de la semiótica y para qué nos sirve (Magariños, 1980). Dicho en términos peirceanos ¿cómo hacer que nuestras ideas sean claras y precisas para otros?

Eco, hasta el Segundo Congreso Internacional de Semiótica de Viena en 1979, había insistido en la necesidad de proceder a una reconstrucción historiográfica del pensamiento semiótico a partir de la época clásica, pues en sus propias palabras señala que se ha "convencido cada vez más de que, para comprender mejor tantos problemas que aún nos preocupan, hay que proceder a la revisión de los contextos en que una determinada categoría apareció por primera vez" (Eco, 1984: 4).

Para ello, Eco propone varios modelos para construir la historia de la semiótica, pero finalmente, aunque es el más complejo, la figura del laberinto de la red o rizoma del callejero resulta más adecuada. Éste es el modelo que Eco (1983: 67) propone para la historiografía de la semiótica porque: "No tiene centro, ni periferia, ni salida, porque es potencialmente infinito. Es espacio de la conjetura" (abducción). Esa localización del conocimiento aporta unos rasgos propios de la semiótica, importa la situación y, también, la perspectiva histórica. El saber es, como en el laberinto, el acopio de un recorrido con muchas rutas. 
Reconocer las matrices históricas de otros tiempos para tener una hoja de ruta de cómo enfrentar las cuestiones del hoy desde una mirada crítica, reflexiva e incluso para revisar algunas prácticas puede ser una guía importante teniendo como referente el pasado. Esa mirada puede mostrarnos cómo se plantearon en otros momentos cuestiones que nos son próximas. Si se quiere avanzar, la semiótica tendrá que hacer algo más que describir y analizar problemas. Castañares nos propone que una vía para la regeneración o refundación de la teoría semiótica solo es posible si se detiene en pensar sobre los grandes problemas de la semiótica en diálogo con otras disciplinas y saber cómo lo hicieron en el pasado para avanzar. Esa es la función de lo que aquí Zemelman (2015) señala que es el pensar epistémico, esto es, el plantearse problemas a partir de lo que observo, pero sin quedarme reducido a lo que observo, sino ir a lo no visto de la realidad y reconocer esas potencialidades que se ocultan, que son las que nos van a permitir construir un conocimiento que nos muestre posibilidades distintas de construcción de la sociedad y el mundo. Braudel (1986), el gran historiador francés, nos recuerda que habría que tener en cuenta que, así como un país no tiene sólo un pasado, tampoco tiene sólo un futuro.

En este sentido, una nueva perspectiva para entender el dominio y los ámbitos que encierra la semiótica obliga a considerar lo siguiente: primero, abandonar la pretensión de objetividad lineal o saberes jerarquizados para dar paso a la interpretación de procesos construidos en un determinado momento histórico. Segundo, incluir otros saberes excluidos o silenciados, hasta la fecha, en los dispositivos hegemónicos de producción y circulación de conocimiento reconociendo su aporte (como, por ejemplo, la cultura aborigen, ancestral, las prácticas sociales, o lo no verbal en general). Tercero, realzar la discusión regional considerando que, si las experiencias históricas son diferentes, los objetos construidos lo serán, puesto que las experiencias también son diferentes en el marco de las culturas vividas.

Entonces, las matrices (a nivel del pensamiento) establecen las bases de una determinada historia de entendimiento a partir de la articulación de categorías y valores. Allí se procesan las distintas vertientes como expresiones del desarrollo teórico. Definir una matriz puede resultar muy útil en el caso de la semiótica (toda vez que allí se pueden observar diferencias y a veces similitudes). Sin embargo, cada una de sus características permite analizar el estado del arte desde una posición distinta; pero siempre sobre una base común (convergencia). Saber cómo se concibe lo social, lo político, es la base para la construcción de diversas matrices semióticas teóricas (Argumedo, 1996).

\section{2. ¿Qué historia de la semiótica puede dar satisfacción a estas necesidades?}

En términos de Eco (2016: 20) "una historia de la semiótica que se ocupe de aquellos autores que hayan reconocido explícitamente la existencia de una relación semiótica en el lenguaje y/o en muchas actividades humanas no verbales, perfilado en una teoría general de los signos, o incluso anticipado el desarrollo de tal teoría como fundamental para las ciencias humanas".

En el caso de Chile, el sentido de pertenencia de los académicos o estudiosos que integran y realizan investigaciones de carácter semiótico, está dada por el quehacer y por la institucionalización. La identidad como categoría es un código emergente que surgió en algunos académicos entrevistados. Estos expresaban que no se sen- 
tían parte del trabajo semiótico, sino que habían realizado investigaciones en algún momento de su carrera o que no estaban dentro del circuito de la investigación semiótica. Hay una coherencia con respecto a la mirada de usar a la semiótica como una "caja de herramientas", lo que hace que puedan abrir o cerrar este dispositivo sin necesidad de adscribir a una identidad con la disciplina; esto se ve reforzado por el carácter interdisciplinar o transdisciplinar del ejercicio de la semiótica que reconocen, en tanto su procedencia disciplinar es diversa y abierta. La identidad a la que se hace alusión reconoce que los problemas semióticos no son permanentes y que en las distintas épocas se han dado distintas respuestas.

Jofré (1997), investigador chileno, protagonista de los inicios de la Semiótica en Chile, reafirma que la historia de la disciplina la revela a la vez como un campo de estudio, una metodología de análisis y una estrategia crítica. De hecho, el tránsito de una época a otra ha hecho que lo que denominamos «Semiótica» comenzara hace dos mil quinientos años atrás, sin tomar plena conciencia de aquello y más bien, se haya fijado como domicilio el siglo XX.

El problema a resolver, entonces, como señala Castañares (2017: 17) recuperando las ideas de Foucault, pasa por tener presente que "la unidad discursiva no hay que buscarla tanto en la coherencia de los conceptos, o más bien, del lado de su emergencia simultánea o sucesiva, de la desviación, de la distancia que los separa y eventualmente de su compatibilidad", sino tener presente que la historia que se propone el investigador es un proceso que conduce de un problema a otro en un continuo, lleno de semiosis infinitas. Por tanto, más que encontrar problemas, lo que existe, según Collingwood (1965: 271), es un "complejo (rizomas) de preguntas y respuestas" distinto en cada momento histórico que ameritan asumirlas con una actitud reflexiva y crítica.

En definitiva, la propuesta de una arqueología semiótica por Castañares (concepto acuñado de Foucault), supondría, un método de "recreación constructiva" (constructive re-enactement), del pasado en el presente siguiendo la idea de Collingwood, (1965: 271 y sigs.).

Esta perspectiva arqueológica de la semiótica propuesta por Castañares, resulta especialmente importante para la disciplina por una razón: hasta finales del siglo XIX no se podía hablar de un "campo de problemas semióticos" o, si se quiere, considerar la necesidad que existiera la "semiótica" como disciplina porque lo que hoy se considera un problema semiótico, en ese momento se planteaban desde otros contextos disciplinarios como los gramaticales, retóricos, lógicos, filosóficos, teológicos, o médicos, entre otros.

En resumen, se trata de convenir la coexistencia de dos procesos: dar cuenta de la tradición recogida a través de la memoria y de una traducción-interpretación por parte de un historiador de aquellos problemas que se relevaron en una época y de cómo esas ideas fueron transitando a otras épocas y a otras culturas en un continuo semiótico. De tal modo, que sólo describiendo esos procesos es posible entender cómo y por qué se plantean los que hoy consideramos problemas semióticos. No es tarea fácil, articular la memoria del pensamiento semiótico, pero tampoco la semiótica puede renunciar a ella. Es cierto que aún no tiene respuestas a las preguntas, ni las tendrá porque su naturaleza epistémica la obliga a plantear siempre nuevas preguntas. La historia de la semiótica que se propone no está obligada a dar soluciones, sino a poner en perspectiva dinámica aquellas rupturas y continuidades del pensamiento semiótico en la que no cabe todo y de la que no podemos esperar el hallazgo de una verdad absoluta y perenne, sino por 
el contrario, se trata de encarar aquellos problemas contingentes a una época que en la medida que se van presentando y cuyas aparentes soluciones que se pudieran presentar hoy, podrían producir mañana otros problemas.

Por último, cuando a Castañares le correspondió coordinar el homenaje a Umberto Eco en la revista deSignis (2017), ya advertía que la diversidad de autores y perspectivas contempladas en dicha edición constituían a modo de ejemplo, una muestra de la inmensidad del territorio a explorar y de la heterogeneidad de los problemas y perspectivas que lo pueblan en el campo de la semiótica.

\section{Salida}

El papel de la historia es clave para entender de alguna manera el estado actual del campo de la semiótica y por qué no, para trazar nuevas rutas y agendas de trabajo investigativo para más adelante. El tema es que las narrativas históricas producidas hasta la fecha han generado una suerte de auto reconstrucción que tienden a ocultar tras de sí, la posibilidad de pensar en las rupturas, continuidades y prospecciones en la realidad vivida lo que en definitiva ha provocado una ilusión de contar con un origen, una fundación, un avance evolutivo y una actualidad visibilizada por todos. De ese modo, se ha construido una unidad en la diversidad según nuestro origen académico, disciplinar, áreas de producción e incluso institucional, legitimando las teorías en resonancia epocal y los mitos fundacionales, generando distorsiones entre lo que es la semiótica, donde ubicarla y qué razones argumentamos para relevar su papel en el concierto de las otras disciplinas considerando que todas usufructúan de la semiótica.

La propuesta es, entonces, revisar nuevamente la historia intelectual nuestra y las teorías que hemos venido siguiendo con la esperanza de incrementar nuestra mirada y visualizar qué historia amerita ser narrada para orientar nuestro trabajo y de paso, por qué no, levantar nuevas propuestas teóricas o quizás otras historias que pudieran enriquecer a la disciplina. Estamos ciertos que una narración histórica nunca es exhaustiva, ni da cuenta de todo lo que consideramos significativo, siempre quedará abierta. Por tanto, la reconstrucción no puede ser acabada, ni tampoco ha sido nuestro objetivo. Como bien lo señalaba Castañares hay que tener presente que se debe renunciar a aspectos igualmente valorables al construir una historia. Nadie ha dicho que mirar el pasado, tener en vista el presente y vislumbrar un futuro, sea una tarea fácil, por el contrario, es compleja, pero necesaria y urgente. Requerimos nuevas narraciones que permitan visualizar, otear, otras historias, otras rutas de cartógrafos que nos faculten pensar sobre y desde la semiótica, la realidad que nos circunda.
A la memoria de Wenceslao Castañares A los que partieron de este mundo $Y$ se transformaron en inspiración Cicerón, Filipina IX.5. 


\section{Bibliografía}

Argumedo, A. (1996). Los silencios y las voces en América Latina. Notas sobre un pensamiento nacional y popular. Buenos Aires: Ediciones del pensamiento nacional.

Beuchot, M. (2004). Hermenéutica, analogía y símbolo. México: Editorial Herder

Braudel, F. (1968). Aportación de la historia de las civilizaciones, La Historia y las Ciencias Sociales. Madrid: Alianza Editorial.

Busso, M. P. (2015). Semiótica del camuflaje. Entrevista a Paolo Fabbri, Revista Letra. Imagen. Sonido. Ciudad Mediatizada. VII, 13, 87-96.

Castañares, W. (1987). Ch.S. Peirce. historia de una marginación, Revista de Occidente 71, 125-142.

Castañares, W. (1990). Historia. identidad y diferencia, Revista de Occidente 104, 146-151.

Castañares, W. (1994). Abduction and traslation among cultures, en P. del Río, A. W. Álvarez, \& J. V. Wertsche (Eds.). Explorations in Socio-Cultural Studies (pp. 48-55), Vol. 1: Historical and Theoretical Discourse. Madrid: Fundación Infancia y Aprendizaje.

- (2014). Historia del pensamiento semiótico 1. La antigüedad grecolatina. Madrid: Trotta.

- (2017). Historia del pensamiento semiótico 2. La Edad Media. Madrid: Trotta.

- (2017). Arqueología semiótica. En Miradas, Lenguajes y Perspectivas Semiótica Aportes desde América Latina. Federación Latinoamericana de Semiótica (FELS) Compilado por Pardo, N. \& Ospina, L. Universidad Nacional de Colombia, Instituto de Estudios en Comunicación y Cultura (IECO), pp. 200-211.

Collingwood, R. G. (1953). Autobiografía. México: Fondo de Cultura Económica.

- (1965). Idea de la historia. México: Fondo de Cultura Económica.

Cruz, J. I. (2006). El pensamiento de Foucault como caja de herramientas, Discusiones Filosóficas, 7(10), 183-198. Retrieved May 30, 2020, from http://www.scielo.org.co/scielo. php?script $=$ sci_arttext\&pid=S0124-61272006000100011\&lng=en\&tlng=es

Eco, U. (1983). Apostillas a El nombre de la rosa. Barcelona: Lumen

Eco, U. (1984). Semiotics and the philosophy of language. London/Basingstoke: The Macmillan Press.

- (2007). Dall'albero al labirinto. Studi storici sul segno e l'interpretatione. Milán: Bompiani.

Eco, U. (2016). Propuestas para una historia de la semiótica. Conferencia pronunciada en el II Congreso de la IASS-AIS, Viena, Julio de 1979. La traducción de este artículo es de Asunción López-Varela Azcárate (Universidad Complutense de Madrid, España). DeSignis, 25, 2016 (julio - diciembre).

Escudero, L. (2017). Una historia necesaria. DeSignis, 25, 11-17

Fabbri, P. (2004). El Giro Semiótico. Barcelona: Editorial Gedisa.

Foucault, M. (2002ª). Arqueología del saber. Buenos Aires, Siglo XXI Editores.

Innerarity, D. (2006). Historia, memoria e identidad colectiva, en D. Innerarity. El nuevo espacio público (pp. 157-167). Madrid: Espasa.

Jofré, M. (1997). Estado del arte de la semiótica actual. Revista Literatura y Lingüística, 10, 191-204, en http://redalyc.uaemex.mx/redalyc/pdf/352/35201010.pdf

Kull, K. y Velmezova, E. (2014). What is the main challenge for contemporary semiotics? Sign Systems Studies, 42(4), 530-548.

Laborda, X. (2011). La lingüística y el historiador perfecto, en Círculo de lingüística aplicada a la comunicación, 46, 51-90.

Lotman, Y. (1996). La semiósfera I. Madrid: Cátedra.

Magariños de Morentín, J. (2008). La semiótica de los bordes, Apuntes de metodología semiótica. Córdoba: Comunicarte. 
Martín-Barbero, J. (2001). Oficio de Cartógrafo. Travesías latinoamericanas de la comunicación en la cultura. Santiago de Chile: Fondo de Cultura Económica.

Martín-Barbero, J. (1988). De los medios a las mediaciones. Barcelona: Gustavo Gili.

Muñoz, B. (2005). Cultura y comunicación: Introducción a las teorías contemporáneas. Madrid: Editorial Fundamentos (V. O 1989).

Parra, E. (2013). Hitos relevantes de la semiótica en Chile a partir del año 1990, en Perspectivas de la Comunicación, 7 (2), 108-118.

Parra, E. y Otazo, J. (2014). Algunas tendencias de la semiótica en Chile a partir de 1990, en VVAA, New semiotics. Between tradition and innovation. (pp. 216-226). Congreso Mundial de Semiótica. Bulgaria.

Peirce, Ch. S. (1897). Fundamento, objeto e interpretante. Texto tomado de MS 798 [On Signs] c.1897, 5 pp. Fue publicado como CP 2.227-229 y 2. 444n1.Traducción castellana de Mariluz Restrepo (2003).

Prieto, L. J. (1977). Pertinencia y práctica. Barcelona: Gustavo Gili.

Serrano, S. (1998). La semiótica, una introducción a la teoría de los signos. Barcelona: Montesinos Editor.

Vidales, C. (2008). Semiótica y comunicología, el desarrollo de una fuente histórica y científica: recuentos, problemas y rutas posibles. Razón y Palabra $\mathrm{N}^{\circ} 61$. Recuperado el 7 de mayo de 2020 de http://www.razonypalabra.org.mx/anteriores/n61/evidales.html

- (2009). La relación entre la semiótica y los estudios de la comunicación: un diálogo por construir, Comunicación y Sociedad 11, 37-71.

- (2010). Semiótica y teoría de la Comunicación. Tomo I. Monterrey, N.L México: Colección Altos estudios No 23.

- (2011). Semiótica y teoría de la comunicación. Tomo II. Monterrey. N.L. México: Colección Altos Estudios No 24.

Zemelman, H. (2015). Pensar teórico y pensar epistémico: los retos de las ciencias sociales latinoamericanas. Publicado por Instituto de pensamiento y cultura de América Latina (IPECAL). Consultado 29 de junio 2018 en: http://www.ipecal.edu.mx/Biblioteca/Documentos/Documento7.pdf. 